II. Two recitations of the French Alexandrine, " Je suis romaine, hélas, puisque Horace est romain.'

$$
\begin{aligned}
& \text { Je surs romaine, nelas, pusqae Horace est nomain }
\end{aligned}
$$

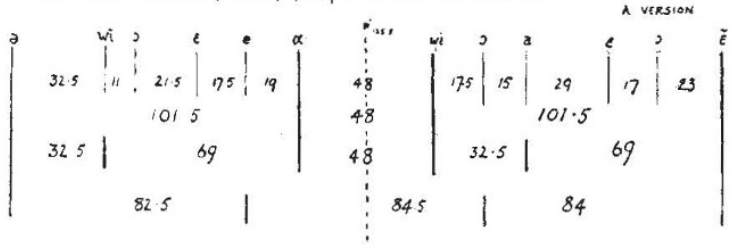

$$
\begin{aligned}
& \frac{25 i}{2} \times 1255
\end{aligned}
$$

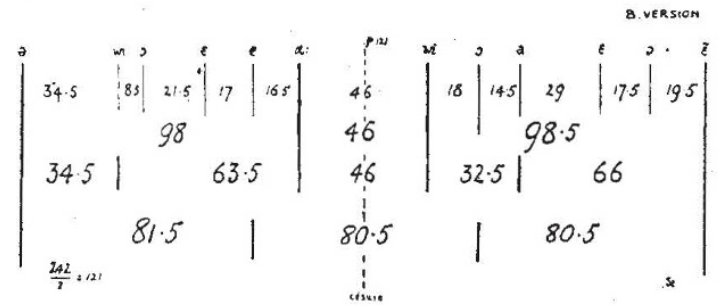

Here in each recitation the addition of intervals results in a central symmetry of identical design (apparently the normal organisation of the isolated Alexandrine); a possible trimetric division is obtainable by utilising the less prominent stresses. It must be noticed that in the $\mathrm{A}$ recitation the time between the initial and final stress maxima is $25 \mathrm{I}$ hundredths of a second. Dividing this by 2 we have 125.5 and on synchronising this point with the voice record we find it to coincide with the closure of the $\mathrm{p}$ in puisque. The same holds true for B version, total 242 ; that is to say, the 'cæsura,' though not itself a stress-point, is situated exactly midway between the first and last stress-maxima. This twin experiment is particularly interesting as revealing (a) a stress-organisation of French verse; $(b)$ the manner in which a reciter while reducing his total time expenditure by 9 in $25 \mathrm{I}$ hundredths of a second, yet accurately apportions the reduction so as to maintain the same organic rhythmical structure.

In this preliminary account of a few among a very large number of experiments, I have been compelled to choose only short examples, and to give of these a very summary interpretation. I may, perhaps, add that more extended records, notably those embracing a complete stanza, yield time-forms of beautifully elaborate and accurate symmetrical structure.

J. W. JEAFFRESON.

\title{
Dutch Pendulum Observations in the Atlantic and the Pacific.
}

\section{By Dr. J. J. A. Muller.}

THE voyage of Dr. Vening Meinesz announced in NATURE of June 5, 1926, has almost been completed. The latest information by letter was from Honolulu; a cablegram reported the arrival at Amboina on November 25 .

H.M. Submarine $K X I I I$. left Helder on May 27 on a calm, sunshiny day, but the weather soon changed and after leaving the channel it was impossible to make any observations above the slope to the deep sea. A few days before sailing the ship had taken in much cargo, especially liquid fuel, and the trim was not known, which made it inadvisable to submerge for the first time in a very rough sea. The first observation was made June 2 , and nearly every day after this date while at sea the pendulum apparatus was used in the submerged ship; on several days more than one and sometimes so many as four observations were made. As on his former voyages, Dr. Vening Meinesz also measured the intensity of gravity in every harbour where the submarine called.

The new apparatus has fully answered to expectations; the pitching of the ship causes no troublesome disturbance, and sliding of the pendulums need not be feared. This apparatus can be used in circumstances in which that used during the former voyage would have failed. A rolling of $3^{\circ} .5$ to both sides was no hindrance to the making of observations. This was a great advantage, as in the Atlantic, at a depth of 20 and more metres, the rolling sometimes reached as much as this. The strong swell in the Atlantic and the Pacific destroyed,the hope that it might be possible to make observations at the surface of the sea.

Unfortunately for the deep sea soundings, the senders of the underwater clock signals were placed too high in the shipboard, in the wave zone. The echo was not a definite sound, and consequently the echo method could not be used for soundings at the surface of the sea; in the submerged vessel the place of the senders caused no trouble. The sonic depth-finder, which had been received only a few days before departure from Helder, has been of no use. Before San Francisco was reached, again and again Commander van der Kun and Dr. Vening Meinesz when trying to detect what was wrong, thought at first it was due to the relay; at length it appeared to be a defect in the construction, which only the maker in London can put right. It is a disappointment that owing to these two circumstances the voyage will contribute in only a limited manner to our knowledge of the depth of the sea on the track. For the determination of the interval of time between the production of the sound and the perception of the echo, a stop-watch of the Royal Navy was used indicating a hundredth part of a second.

The time signals used were at first those of Bordeaux, which were audible so far as Mona Passage, and afterwards those of Annapolis, which could be perceived for some days after leaving San Francisco. The use of the signals of Balboa and San Diego could be dropped, and the Naval Observatory at Washington was informed that these stations need not be controlled. In the whole Pacific the time signals of Lembang, given by the powerful radio station of Malabar (Java) can be used; these were clearly audible in Curaçao. The Nardin chronometers were the same as were used on the voyage in 1925 ; the regularity of the run of both was marvellous. For the comparison of the chronometers with the rhythmic time signals, Dr. Vening Meinesz intercalates the interrupter of the mean time chronometer in the telephone circuit and observes the appearance and the disappearance of the time signals; in this way the personal equation is almost entirely eliminated.

After taking an observation, the film was as a rule immediately developed; often it was directly measured and the preliminary result computed. Only when the temperature was too high was the developing put off until the next harbour was reached. Dr. Vening Meinesz estimates that the difference between the preliminary results will not exceed $0.005 \mathrm{~cm} . / \mathrm{sec}^{2}{ }^{2}$; the isostatic reduction, however, will produce much greater differences. In this connexion it will be wise not to arrive at far-reaching conclusions immediately with regard to the prevailing theories NO. 2982, VOL. II 8 ] 
of the constitution of the earth's crust, but to wait until the final computations are to hand.

The number of observations on sea at the different passages so far as Manila is as follows :

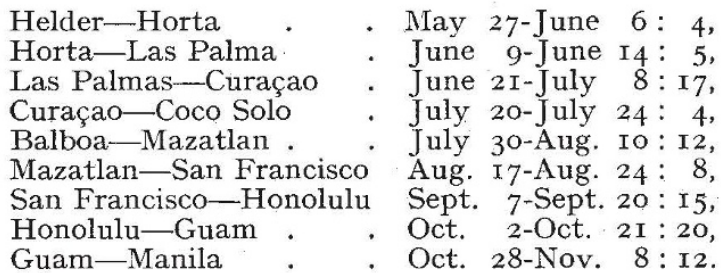

The total number is 97 ; up to November 8 the number of observations made at sea and in the harbours is 106 altogether.

With the reservation just made, I give the following particulars about the anomalies shown by the preliminary results. The anomalies refer to the Helmert formula of $\mathrm{IgOI}$ and are expressed in $\mathrm{cm} . / \mathrm{sec}{ }^{2}$ or dynes.

The first observation gave a normal gravity :

June $2,44^{\circ} 12^{\prime} \mathrm{N}$., $15^{\circ} 33^{\prime} \mathrm{W}$., sea-depth 5000 metres, anomaly +o.004.

The three following gave an excess :

June $3,43^{\circ} 13^{\prime}$ N., $18^{\circ} 46^{\prime}$ W., sea-depth 4350 metres, anomaly +o.055

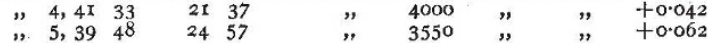

The last was above the mid-Atlantic ridge.

At Horta the anomaly was +0.126.

Eastward -from the ridge the anomaly diminished to 0.016 ; near the north coast of Teneriffe the coast effect was shown by an anomaly of $-0 \cdot 008$.

At Las Palmas the anomaly was $+0 \cdot 2$ Io. According to a communication from Dr. Bowie, it is reduced to +0.089 by applying the isostatic correction.

After leaving Las Palmas the first three observations gave the following anomalies:

$$
\begin{aligned}
& \text { June } 22,27^{\circ} 12^{\prime} \mathrm{N} \text {., } 17^{\circ} 5 \mathrm{I}^{\prime} \text { W., sea-depth } 36 \mathrm{ro} \text { metres, anomaly }+0.040
\end{aligned}
$$

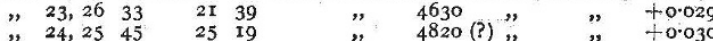

On July 25 , the sea being very smooth, an observation was made at the surface, but at intervals a heavy swell occasioned excessive amplitudes of the pendulums and no result could be obtained. The attempt has not been repeated.

On the following days the anomaly amounted to from $+0.0 I_{5}$ to +0.029 as the sea-depth diminished from 6400 to $394^{\circ}$ metres. The next observation was made on the ridge.

June $30,23^{\circ} 2 I^{\prime}$ N., $47^{\circ} z^{\prime}$ W., sea-depth 3460 metres, anomaly +o 046 .

On July I, sea-depth $45^{20-5820}$ metres, the anomaly was $+0 \cdot 030$.

In the Atlantic between $32^{\circ}$ and $54^{\circ} \mathrm{W}$. the depth of the sea often showed great changes; the interval between the sound and the echo varied in the moving vessel in a few minutes by several seconds and then again returned to its former value. The sea bed seems to be extremely rugged there. The sea-depths also showed great differences from those given on the "Cartes bathymétriques des Océans" of the Prince of Monaco.

Farther west the gravity was normal :

July $2,22^{\circ} 45^{\prime}$ N., $54^{\circ} 35^{\prime}$ W., sea-depth 5760 metres, anomaly +0.002
$58 \quad 27$

Getting nearer to the Porto Rico deep, the gravity increased :

July $4,21^{\circ} 35^{\prime}$ N., $63^{\circ} 21^{\prime}$ W., sea-depth 5480 metres, anomaly $+0 \cdot 023$

$" 5,2042653^{\circ}, " 5290^{\circ} ", "$ to.03I. NO. 2982, VOL. I I 8$]$
This last observation was at the edge of the deep.

July $5,19^{\circ} 30^{\prime} \mathrm{N} ., 66^{\circ} 5 \mathrm{I}^{\prime} \mathrm{W}$., sea-depth 7660 metres, anomaly $-0^{\circ} 32 \mathrm{x}$, above the deep but not at the greatest depth.

July $6,18^{\circ} 42^{\prime} \mathrm{N} ., 67^{\circ} 42^{\prime}$ W., sea-depth 290 metres, anomaly +0.005 , in Mona Passage.

Before reaching Curaçao an observation was made in the Caribbean Sea :

July 6 , $16^{\circ} 54^{\prime}$ N., $67^{\circ} 42^{\prime}$ W., sea-depth 4740 metres, anomaly -o'oo6.

In the harbour of Willemstad (Curaçao) the anomaly amounted to $+0 \cdot 174$.

Between Curaçao and Colon the Caribbean Sea showed a deficiency of gravity; in the harbour of Coco Solo (Colon) the anomaly was +0.083 and in that of Balboa (Panama) +0.094.

On July $3 \mathbf{I}$ the first two observations in the Pacific were made, but unfortunately they were both failures, the film being insufficiently extended, so that it was wrinkled and got torn. Before reaching Coco Solo there had been some difficulty in changing the speed of the film, the tension being too great, so it had been slackened. Since this experience the tension of the film has caused no further difficulty.

Along the west coast of America from Balboa to San Francisco the number of successful observations was eighteen at sea and one in the harbour of Mazatlan; so far as this harbour they showed an excess of gravity.

Aug. I, $7^{\circ} \mathrm{I}^{\prime} \mathrm{N} ., 82^{\circ} 38^{\prime}$ W., sea-depth 3020 metres, anomaly $+0.06 \mathrm{r}$



On Aug. 6 a set of four observations was made in a profile nearly perpendicular to the coast :

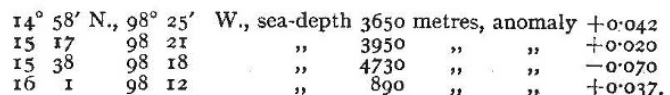

Aug. 8 a set of three observations :

$\mathrm{r} 7^{\circ} 30^{\prime} \mathrm{N}$, ror $^{\circ} 2 \mathrm{r}^{\prime} \mathrm{W}$., sea-depth 4990 metres, anomaly - 0.076

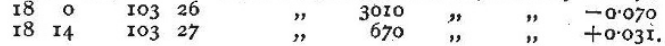

In the harbour of Mazatlan the anomaly was $+0 \cdot 036$.

On July I9 a set of three observations was again made; the results have not yet been received Along the U.S. Pacific coast the gravity was normal. After leaving San Francisco a last set of three observations was made for the study of the coast effect.

In the eastern part of the Pacific the gravity was at first normal ; after half the way to the Sandwich Islands had been covered it showed a positive anomaly: Sept. I $4,28^{\circ} 57^{\prime}$ N., $141^{\circ} 16^{\prime}$ W., sea-depth 4920 metres, anomaly $+0.030^{\circ}$ "18,22 57 I53 4I " 4540 " " +0.065.

It appears that the excesses of gravity in the Atlantic and the Pacific extend over enormous areas, while the excesses or defects on the continents possess a more limited, regional character.

The preliminary results of the observations do not show any trace of a flattening of the equator; it may be expected that this problem will be solved by the final results.

The long voyage from Las Palmas to Curaçao, I7 days, from San Francisco to Honolulu, I3 days, and from Honolulu to Guam, I9 days, was very strenuous, and the relaxation in the harbours was well deserved. In every harbour at which the submarine called, the crew met with the most cordial reception. Scientific workers, especially at San Francisco and at Honolulu, took much interest in Dr. Vening Meinesz and his work. In the latter place he met a number of delegates to the Pan-Pacific Congress on their voyage to Tokyo.

Thus far the voyage, the longest ever made by a submarine, has been very successful. If all goes well Dr. Vening Meinesz should have reached Surabaya 
about December xo; he will then stay at Java for some time to recover from the fatigues of the voyage before his return home on board a mail steamer. It may be recorded with satisfaction and thanks that the commander, the officers, and the crew of the submarine did all they could to facilitate the fulfilment of his task.

After the receipt of particulars about the rest of the voyage up to the arrival at Surabaya, I propose to give a brief account of the later results and to complete the present information.

Since the above was written, I have received from Washington the isostatic reductions of the observations made between Helder and Curaçao. These have been computed by the U.S. Coast and Geodetic Survey as a token of appreciation of the work of Dr. Vening Meinesz, which is justly considered to be of international interest. I must express here a word of thanks for this valuable co-operation, especially to Dr. William Bowie, Chief of the Division of Geodesy.

For the present it may suffice to mention that the excess of gravity in the Atlantic is confirmed, after the isostatic reductions have been taken into account.

\section{The Burning of Carbonic Oxide.}

I $T$ was a sound movement on the part of the directors of the Gas Light and Coke Company to invite Prof. Bone to lecture before the Company and others on the work which he is carrying out on gaseous combustion, and particularly on the investigations made by Mr. F. R. Weston, the first holder of the Gas Research Fellowship, founded by the Company three years ago, at the Imperial College of Science. Prof. Bone had no difficulty in proving what important scientific results can be secured by means of such endowments of research, and Mr. Milne Watson, governor of the Company, showed that he realised that the development of chemical industries depended on the successful prosecution of strictly scientific investigations in the laboratory.

After comparing and contrasting the flames of hydrogen and carbonic oxide, and the effect of their mixture in water-gas, Prof. Bone took up the tale of the burning of carbonic oxide as it began to be studied in Oxford fifty years ago, when $\mathrm{H}$. B. Dixon, in repeating Bunsen's experiments on the distribution of oxygen between hydrogen and carbonic oxide, showed that the latter apparently did not react directly with oxygen but was oxidised by the steam, and that the final division of the oxygen depended on an equilibrium being established between this and the reverse action-the reduction of the carbon dioxide by the hydrogen :

$$
\mathrm{CO}+\mathrm{H}_{2} \mathrm{O} \longleftrightarrow \mathrm{CO}_{2}+\mathrm{H}_{2} \text {. }
$$

The non-inflammability of dried mixtures of carbonic oxide and oxygen led to many conjectures as to its cause, and as to the mechanism of steam in the reaction. That no chemical reaction can take place without 'conducting' water; that liquid water particles are the necessary electrical go-between ; that gases can only react molecule with molecule, i.e. in equal volumes; that the oxygen molecule is too stable to be broken up, but steam is more yieldingthese and other explanations were advanced by men of scientific eminence. For some years Dixon has held the more prosaic view that the direct oxidation of carbonic oxide in explosions is limited by the thermal dissociation of the carbon dioxide molecules, and that steam afforded the means of producing comparative cool molecules. The burning of dry cyanogen and the direct union of carbonic oxide and oxygen in contact with heated platinum seemed to show that steam was not essential, but this and the function of the steam were matters of inference. No direct proof of what happened in the flame was forthcoming.

Prof. Bone, whose first research on gaseous combustion, carried out at the Owens College, was the study of the slow union of carbonic oxide and oxygen when circulated over heated surfaces, now brings forward direct evidence of two kinds. He shows, first that a very well-dried mixture of the two gases, which cannot be inflamed by an ordinary spark, can be exploded (at all events partially) when the electric discharge is made sufficiently powerful. In such conditions the flame traverses the bulb containing the mixture, though not with violence, and a large percentage of the gas combines in the flame. Again, Prof. Bone and Mr. Weston have shown that as the moisture is gradually removed from the mixture, the energy of the condenser discharge required to ignite it progressively increases. Lastly, the spectra of the flames of the well-dried mixture, the moist mixture, and of mixtures containing hydrogen have been photographed. The flame of the dried mixture burning under 25 atmospheres pressure shows a continuous spectrum and no steam lines. The flame of the undried mixture shows a strong continuous spectrum overlying a 'steam-line' spectrum. On the addition of hydrogen the continuous spectrum grows less and the lines emerge, so that there is direct evidence that two reactions are taking place simultaneously in the ordinary flame-the direct oxidation of carbonic oxide by oxygen, and the indirect oxidation by steam. The intense electric discharge, on one hand, and the high pressure on the other, can confer on carbonic oxide the power of direct union with oxygen; in the presence of much steam the indirect reaction is predominant; with traces of steam both reactions occur together.

\section{University and Educational Intelligence.}

Birmingham:-The degree of D.Sc. has been awarded to Sydney Raymond Carter for numerous published papers on the oxidising properties of sulphur dioxide and other subjects.

LEEDs.-Sir Berkeley Moynihan, Bart., has resigned the professorship of surgery on his retirement from the full staff of the Leeds General Infirmary. In recording its regret at Sir Berkeley's retirement, the Council referred to his brilliant career as student in the Yorkshire College, with which the I-eeds Medical School became incorporated, and after. " Throughout his career he has followed the tradition of the Leeds Medical School in bringing scientific knowledge into the service of surgery. With this he has associated a consummate skill in the art of surgery, thereby contributing substantially to the efficacy of surgical methods and the accuracy of diagnosis."

LONDON.-A lady, who desires to remain anonymous, has offered the University the sum of Io, oool. towards the establishment of a chair of dietetics.

Subject to certain conditions, the offer of Mr. J. G. Wilson to present to the University a 24 -inch reflector telescope has been accepted. Lady Godlee is giving a sum of money, to be held in trust for University College and University College Hospital Medical School, to found a Rickman Godlee Lectureship in memory of her husband, the late Sir Rickman J. Godlee. The managing director of the Vultex Products, Ltd., on behalf of Mr. Patrick Gow, is to give a sum of money for three years for lectures on colloidal chemistry.

NO. 2982, vOL. II 8$]$ 